\title{
A ERA DO MOBILE LEARNING E DA UBIQUIDADE, REFLEXÕES NO DESTERRO, DESAFIOS PARA ALÉM DA ILHA, SOBRE PRÁTICAS PARA OS “CIBER” PROFESSORES
}

\author{
CAMPINA GRANDE DO SUL/PR MAIO/2018
}

\author{
ODY MARCOS CHURKIN - SEED-PR - odymarcoschurkin@gmail.com \\ Tipo: Relato de Experiência Inovadora (EI) \\ Categoria: Métodos e Tecnologias \\ Setor Educacional: EDUCAÇÃO MÉDIA E TECNOLÓGICA
}

\begin{abstract}
RESUMO
Diante ao cenário que o século XXI apresenta em seu florescer, vislumbra-se mudanças imensuráveis nas tecnologias de comunicação e informação (TICS) somadas ao que se pode dizer como um marco civilizatório, o surgimento e aprimoramento da internet, causando uma transformação nos ethos da sociedade mundial, tempo e espaço virtualizados. Vive-se a era da conetividade, o mundo se faz a Pólis virtual e sua Àgora estampa-se de forma ubíqua nas telas dos dispositivos móveis. A partir da contextualização deste momento ímpar da história, o objetivo principal deste artigo é demostrar e compartilhar com a metodologia de um estudo de caso, algumas experiências em sala de aula com a adoção do mobile lerarning, com idicativos de projetos da UNESCO, NM HORIZON e NOKIA, sob um viés da fenomenologia para a adoção da mobilidade, ubíquidde e da conectividade no ensino aprendizagem na era da cibereducação. Enfatizar com auxílio de uma reflexão pautada na filosofia da tenologia, que as TICS são meios para formação epistemológica e ontológica e não apenas "fins" instrumentais. Refletir sobre os sujeitos como atores na produção do conhecimento com auxílio das TICS e não apenas consumidores, sem perder de vista a diversidade, cidadania e a cooperação na teia global da modernidade líquida. Enfatizar o papel do professor e da criatividade, frente à era da ubíqua, além do que, demonstrar que há como tirar proveito de seus próprios dispositivos, para práticas em sala de aula, tornando-se um mediador e curador no mobile learning. A importância da empatia para delegar e aceitar instruções para a adoção de novos procedimentos com novos dispositivos e processos. Incentivar e orientar professores para se obter uma ciber formação, com uma visão holística e sistêmica para se encontrar e ou se criar inúmeras possibilidades no ensino e aprendizagem do novo paradigma que se apresenta.
\end{abstract}

Palavras-chave: Conectividade. Holística. Mobile learning. Paradigma. Ubiquidade.

\section{AGRADECIMENTOS}

A DEUS,

PARA ESTA OPORTUNIDADE ÍMPAR;

AOS QUE ME AMAM ;

PARA CRÍTICAS SEVERAS;

PARA A POSSIBILIDADE DA DIALÉTICA E

AOS MEUS DESAFETOS, QUE ME POSSIBILITAM A CONHECER-ME E SUPERAR-ME A CADA INSTANTE. 


\section{INTRODUÇÃO}

Após quinze anos lecionando filosofia para o ensino médio, tenho observado que a cada ano que finda, o desinteresse dos alunos para atividades pedagógicas aumenta, não obstante para o que concerne a utilização de teconologia de informação e comunicação (TIC) é inversamente proporcional.

Estão conectados e interligados ao mundo virtual e obíquo, visto que a cada instante as tecnologias se superam, sendo intensas as mudanças, assim como os seus relaionamentos, deixa-os fascinados, as novidades são objetos de desejo, por mais complexos que sejam os dipositivos e seus aplicativos. Esclarece Hetkowski, et al (2014):

\footnotetext{
Há a necessidade urgente de aproximação do universo e da cultura dos alunos, torna-se essencial contextualizar os processos de ensino e aprendizagem, ressignificando as possibilidades educativas e o uso da tecnologia na escola e fora dela. Nessa procura, pelo redimensionamento do "ensinar e aprender", abrem-se possibilidades alternativas a lógica instituída. (Hetkowski, et al 2014, p.78).
}

No entanto, notei que um assunto ou conteúdo da disciplina chama a atenção dos jovens aprendizes, a mitologia grega, em especial a Teogonia, os deuses e semideuses com seus inúmeros poderes, especificidades, segredos e muitos conflitos e guerras. Diz Jacinsky (2004), "As próprias tecnologias audiovisuais incorporam-se de tal modo nas relações sociais e na subjetividade que não podem ser encaradas como meras ferramentas".

Surpreso e intrigado pelo súbito interesse na interseção dos anos e das aulas, constatei que por intermédio de seus jogos (games) em seus celulares ou computadores, reconeceram as personagens nas lições de filosofia, no caso dos mitos gregos, fato que os deixa com um comportamento diferenciado, em relação a uma rotina de apatia e distanciamento ao aprendizado escolar. Explana Candido (2005):

\footnotetext{
Desse modo, todos aqueles que desejam filosofar, ensinar e aprender a filosofia, realizar o diálogo filosófico hojenas salas de aula e fora delas - estão convidados não apenas a conhecer, mas fundamentalmente a se apropriarem criativamente da admirável rede do lógos dialético hipertextual que unifica a mente humana em sua infinita riqueza e diversidade (CÂNDIDO, 2005, p. 225).
}

Pelo fato de conhecerem de alguma forma parte do conteúdo apresentado, os torna participativos, portanto é nítido um comportamento que se destoa da rotina do niilismo convencional, não obstante uma sensação de pertencimento e até mesmo de empoderamento de um público geralmente desacriditado. Reforça-se, quando podem demonstrar o conhecimento técnico em relação às TICS, há iniciativa e até mesmo 
afetividade. De acordo com Oliveira (2008, p. 108):

(...) vemos a relação entre meios massivos e a escola de ensino médio. Esta (...) tem de aceitar a tarefa da busca de novas formas de estabelecer mediações entre seus alunos e um universo de imagens que Ihes cercam diariamente - o que não significa, por outro lado, abandonar a cultura escrita. Trata-se, pois, de não se cair no discurso da negação, rejeitando completamente o novo cenário cultural que se nos apresenta, tal como se a cultura midiática e a cultura escolar representassem dois campos opostos e inconciliáveis. (OLIVEIRA, 2008, $p$. 108):

Fazem questão de descreverem seus saberes e conhecimentos, portanto a situação me causou muita inquietação, curiosidade e motivação em saber que algo em relação à escola os interessa. Conforme Pommer (2006) "Pode ser também que estejamos inventando um outro tipo de oralidade e escrita, justamente aquele que poderá ser capaz de comunicar-se entre si de modo mais eficiente.".

Constatar mudanças nos causa desconforto, insegurança, e há apenas dois caminhos a seguir, a inovação ou permanecer em uma zona de conforto, com a intenção de procrastinação. Para não se arriscar e ou deixar uma construção inteira que corre o risco de desaparecer. De acordo com Xavier (2010):

Há uma nostalgia comum, um discurso de perda, de conservação, um apelo a um passado impossível de ser mantido. Todavia, há que se considerar as diferenças, não apenas quanto ao ser da palavra e o ser, mero clichê, da imagem midiática, mas também a diferença nos modos/efeitos de suas "capturas" e suas relações com a experiência da temporalidade. (XAVIER, 2010, p.38)

Esta evidência, a luz da fenomenologia transformou-se em objeto de pesquisa, e levantou-se uma hipótese, se a mitologia grega e as novas tecnologias causam tanto impacto na psique do jovem e estimula algum interesse (fetiche) aos jovens, "tudo isto evidencia a importância de fazer uma reflexão que aborde seriamente o fenômeno tecnológico e suas conseqüências sobre a humanidade" (Klinge, 2003).

Por que não inovar e apicá-las de alguma forma nas aulas de filosofia e expandir ou compartilhar com outras disciplinas? Como? "O contrário é convergente e do divergente nasce a mais bela harmonia, e tudo segundo a discórdia" já dizia Heráclito de Éfeso (VI A.C).

A ideia foi aproveitar o que já está presente no cotidiano, ou melhor, literalmente nas mãos, pois não se oferece resistência ou repulsa, ao contrário, fomenta inúmeras possibilidades e perspectivas; sem a intenção de defender um pensamento quixotesco ou utópico, ao contrário, sutentado e justificado pela filosofia da tecnologia, para o ensino aprendizagem, processo conceituado de mobile learnig. 
Portanto com o auxílio da direção e do corpo pedagógico foi implementado o mobile learning com auxílio do projeto da UNESCO/NOKIA "Bring Your Own Device" (BYOD) de 2014, nas aulas de filosofia no Colégio Rui Barbosa, localizado em Colombo no Paraná, região metropolitana de Curitiba no Paraná, no Sul do Brasil, para as turmas do ensino médio.

Traga o Seu Próprio Dispositivo (BYOD) Uma forma viável de conseguir um ambiente 1:1 é fazer com que os alunos usem os dispositivos que já têm em casa. Conhecido como BYOD, o modelo vem causando uma mudança sem precedentes na educação superior e no ensino a distância ao permitir que mais alunos acessem os materiais pedagógicos através da tecnologia móvel. (UNESCO, 2014, p.20,21).

No primeiro trimeste do ano de 2018, o mobile learnig começou a ser aplicado, visto que a chamada escolar nos Colégios estaduais do Estado do Paraná, já pode ser realizada pelo celular, tablet ou laptop do professor, online, ou seja, de forma ubíqua, ou posteriormente em quaquer dispositivo conectado à internet. Além do que lançamentos e observações eventuais no diário de classe, eis a prática do mobile leraning!

Todos diários de classe já cabem no bolso, armanezados em um apicativo no celular do professor, inovações ocorrendo, pequenos passos com grandes reflexos, porém despercebidos!

O mobile learning com os alunos está ocorrendo com atividades de revisão em forma de questionários de múltiplas escolhas e do tipo falso e verdadeiro por meio do aplicativo Socrative, acessando uma sala de aula virtual, onde as questões são preparadas pelo professor. A priori os trabalhos estão sendo realizados em equipes, para cada, utilize apenas um aprelho de celular, além de evitar alguma forma de exclusão, sem dizer reforçar o trabalho cooperativo e coletivo.

A priori a atividade foi assistir um "clipe" sobre alguns filósofos, um filme e um texto, que a posteriori, a partir da entrada na sala aula de virtual, começaram a responder, as atividades propostas pelo professor, inclusive os alunos que não estavam presentes, pois podem acessar a sala de aula virtual em qualquer lugar e horário, portanto 0 sistema acolhe os enfermos e gestantes ou alguma forma de ausência.

No entanto mesmo com as novas tecnologias o papel do professor continua a ser de motivar, orientar e agora adequar um conteúdo específico com a nova tecnologia a ser utilizada, sem dizer que se torna um curador, escolher o melhor da tecnologia para promover o melhor desempenho e entendimento para o seu aluno, a tecnologia auxília e não substitui o professor. 
Dentro deste contexto reforça-se com uma indicação da UNESCO (2014):

Observa-se no Brasil que muitos professores ainda apresentam resistência e outros tipos de dificuldade para utilizar computadores, notebooks, tablets, e até smartphones. Ainda é muito comum a ideia de que esses dispositivos tecnológicos atrapalham o aprendizado por desviarem o foco do aluno do suposto conteúdo em meios impressos que deveriam aprender. UNESCO (2014, p.25).

Desafio lançado, sendo uma das vantagens para utilização de meios que já são empregados no dia a dia de professores e da maioria dos alunos. Os passos iniciais, o incentivo a convivência e cooperação são conceitos essenciais para um novo tempo ou nova era.

\section{OBJETIVO GERAL}

Por em prática o projeto experimental, mobile learning nas aulas de filosofia, do ensino médio, como um novo recurso tecnológico e de inovação no Colégio Estadual Rui Barbosa em Colombo no Paraná como um experimento e estudo de caso.

\subsection{OBJETIVOS ESPECÍFICOS}

Tornar a sala de aula, uma incubadora de práticas e ideias, a partir dos projetos da UNESCO/NOKIA o "Bring Your Own Device" (BYOD), conciliado com o Ensinar respeito por Todos (ERT).

Apresentar um processo inovador nas aulas de filosofia. Incentivar os professores e alunos a conhecerem e praticarem o mobile learning e compartilharem das novas experiências adquiridas.

\section{METODOLOGIA}

Desenvolve-se um projeto em andamento de cunho experimental a partir de uma ação com alunos e prossegue agora para com os professores. É um estudo de caso, com a itenção de propor novas estratégias para a educação. Conforme a UNESCO (2016):

\footnotetext{
Reafirmação de uma abordagem humanista à educação. Isoladamente, a educação não pode esperar resolver todos os desafios relacionados ao desenvolvimento, mas uma abordagem humanista e holística da educação pode e deve contribuir para alcançar um novo modelo de desenvolvimento. (UNESCO, 2016).
}

Como preparação para o paradigma se apresenta, para se compartilhar ações e seus resultados, analisar críticas e sugestões, para aprimoramento da mobilidade no ensino aprendizagem como um processo de inovação na educação. 
Sem dizer um instrumento para facilitar o entendimento da cidadania e diversidade, segundo o projeto Ensinar respeito por Todos (ERT) da UNESCO (2018):

As educações para a cidadania e educação cívica se concentram no desenvolvimento da cidadania ativa e da competência cívica ao transmitir o significado único, as obrigações e as virtudes da cidadania nas sociedades nacional, regional e local. (ERT, 2018,p.35).

Trata-se de um estudo de caso, portanto é profícua a escolha de YIN (2015), que orienta e incentiva a investigação com: entrevistas, documentação, observações diretas, registro em arquivos, artefatos físicos e observações participantes.

\section{RESULTADOS}

A recepção dos alunos com a novidade é formidável, muitos se interessam, o mais interessante e que causa "espanto", realizam as atividades sem enfrentamentos ou reclamações.

Cultiva-se um ambiente de curiosidade, euforia e iniciativa, pois já que dominam a técnica e com auxílio do professor o trabalho ser torna "recepetivo" e cooperativo, a autoestima dos jovens é alimentada, "percebem-se empoderados," em um "pertencimento " no sentido ontológico, tornando a escola uma extensão de seu mundo.

O projeto está em andamento com muitos objetivos sendo alcançados. Os desafios são propostos, acompanhados e registrados. As resistências são encaradas com muita resiliência, pois o novo causa crise, desconforto e medo.

Para os integrantes os desafios transformam-se em aprendizado, práxis e a possibilidade de superação e criação. O pleno exercício da crítica e da dialética.

\section{REFERÊNCIAS}

ABBAGNANO, N. - História da Filosofia, I, tradução de A. B. Coelho e outros, Editorial Presença, 5a edição, Lisboa, 1991.

FEENBERG, A. What is philosophy of technology? Lecture for the Komaba undergraduates. 2003. Disponível em:. Acesso em: 3 nov. 2014.

JACINSKY, E. Os desafios educacionais da cultura audiovisual: considerações para o ensino de filosofia. Ed. UNIJUI, IJUÍ-RS, 2004. 
HETKOWISKI, T. M.; MULLER, D. N.; AXT, M. Cultura digital e espaço escolar: diálogos sobre jogos imaginários e crianças. Salvador: EDUNEB, 2014.

KLINGE, Germán Doig. Tecnologia, Utopia e Cultura. 13 p. Disponível em. Acesso em: 21 de abril de 2003.

OLIVEIRA, Adriano Machado. Jovens e adolescentes no ensino médio: sintomas de uma sistemática desvalorização das culturas juvenis. Dissertação de mestrado. UFSM, Santa Maria - RS, 2008.

POMMER, Arnildo. Das epístolas aos E-mail: é possível ensinar filosofia à distância?In.Filosofia na universidade. Org. Maamari et all. ljuí: Ed. Unijuí, 2006.

XAVIER, Ingrid Müller. O que significam aprender e ensinar filosofia? Notas a partir de uma experiência no Colégio Pedro II. Tese apresentada ao Programa de PósGraduação em Educação da UFF. Rio de Janeiro. 2010.

UNESCO. O Futuro da aprendizagem móvel: implicações para planejadores e gestores de políticas. Brasília, 2014. . Repensar a Educação, Rumo a um bem comum mundial, Brasília, 2016.

- . Teaching Respect For All: Implementation Guide, Brasília, 2018. 